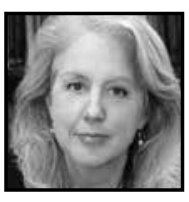

\title{
A Tale of Two Teachers: Learning to Teach Over Time
}

\author{
Marilyn Cochran-Smith
}

From "A Tale of Two Teachers: Learning to Teach Over Time," by Marilyn Cochran-Smith, 2012, Kappa Delta Pi Record, 48, pp. 108-122. Copyright $\odot$ Kappa Delta Pi. Reprinted with permission.

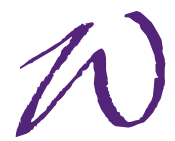

hen I was preparing to be a teacher in the early 1970s, it was believed that people learned to teach through "training." Prospective teachers entered training programs - usually 4-year teacher education programs at colleges or universities - where, in addition to general education courses, they were introduced to important ideas about human development and schooling, equipped with teaching methods in the subject areas, and then, in the spring of their senior year, sent out to "practice" teaching.

Later, when they had become slightly more experienced teachers, they participated with everybody else in periodic "staff development" days, which usually meant that teachers from all the schools in one district were congregated in the high school auditorium to receive the latest information from educational experts about new ways of teaching or best teaching techniques. From this perspective, it was assumed that learning to teach was a single event that occurred prior to teaching, which was later supplemented with smaller updating events over the years.

By the 1980s (and continuing through the 1990s and beyond), things had changed. Newer images of teacher learning were informed by ideas about teachers as reflective practitioners who thought deeply about their work and made decisions in the classroom. The emphasis shifted from what teachers did to what they knew, what their sources of knowledge were, how those sources influenced their work in classrooms, and what conditions and contexts supported their learning. Teacher education programs were organized so that prospective teachers got into classrooms much sooner-during their sophomore or even freshman years - to get an early sense (from the other side 
of the desk) of the day-to-day work of teaching and the complex set of responsibilities teachers have to juggle. In many places, there were also opportunities to gain initial teacher education in graduate-level programs.

Eventually, educators came to think of learning to teach as something that happens over time, not at just a single period of time. We began to work from the premise that learning to teach is a process, not an event. Increasingly, school districts encouraged (and sometimes required) teachers to work together in ongoing learning communities to look closely at their own practice in order to improve their work.

In today's policy and political climate, where teacher quality is widely assumed to be the single most important influence on students' learning, viewpoints about where, when, and how people learn to teach are mixed. However, most teachers and teacher educators continue to believe that teachers learn how to teach over time. In fact, it is widely agreed in the teacher education community that we are never finished learning to teach because each new group of school students brings new challenges and possibilities, and because, as society changes, the issues and problems teachers confront also change. People who see things this way maintain that we need to build into the daily work of schools opportunities for teachers to closely observe their students and investigate how to meet their needs as learners; to do this, teachers need time to meet, raise questions, and develop local knowledge.

\section{A Tale of Two Teachers}

This article looks closely at two teachers who had very different experiences during their first year of teaching. Juxtaposing their experiences helps explain what it means to learn to teach over time. Conveying their experiences in the form of story illuminates the contradictions and tensions that are inherently part of this process.

Literary theorist Barbara Hardy $(1978,12)$ once asserted that narrative should not be regarded as an "aesthetic invention used by artists to control, manipulate, and order experience, but as a primary act of mind transferred to art from life." Elaborating on the primary role of story in our lives, Hardy $(1978,13)$ suggested:

[Stories play] a major role in our sleeping and waking lives. We dream in narrative, daydream in narrative, remember, anticipate, hope, despair, believe, doubt, plan, revise, criticize, construct, gossip, learn, hate and love by narrative. 
From this perspective, narrative can be regarded as a central way we organize and understand experience. It is also a primary way we construct our multiple identities as human beings for whom race, gender, class, culture, ethnicity, language, and position make a profound difference in the nature and interpretation of experience. Story has the capacity to contain and entertain within it the contradictions, nuances, tensions, and complexities of learning to teach in the early years that traditional academic discourse, with its more distanced impersonal voice, often lacks.

The two stories that follow have many similarities - and many differences - that get at some of the nuances of teacher learning in the early years and of continuing to learn to teach across the professional life span.

\section{The Tale of Gill Maimon}

We begin with the tale of Gill Maimon. Like the vast majority of teachers in the United States, Gill is a white, middle class woman. She entered teaching in her midtwenties. After college, she worked for a few years at several jobs related to the media and politics. Unlike some U.S. teachers-especially those who are widely critiqued by the media and policy makers who claim that teachers tend to come from the lowest levels of college students and thus have a weak academic background-Gill had a very strong academic background. In fact, Gill had attended a prestigious liberal arts college in the northeastern United States where she took an interdisciplinary major related to semiotics, literature, and society, which mixed literature study with political science.

Gill was a highly successful student, scoring well on standardized tests and placed in honors and other advanced classes in high school. Gill began teaching with a strong commitment to the profession, even though she did not plan to teach forever. She said she had always known she wanted to teach, but she planned to teach for three years or so and then move into education policy, which would match well with her college study of political science and her experience in politics.

Gill attended a major university for teacher preparation, a university whose school of education was ranked within the top 15 education schools in the country. She enrolled in a one-year master's program that led to initial teacher certification at the elementary school level, kindergarten through grade six. Gill told me in an interview that she chose her institution because of its urban location and because she wanted "rigor." Gill's preparation program had teacher research as its centerpiece and focused on preparing teachers to "teach against the grain" (Cochran-Smith 1991) of the common assumptions and school arrangements that perpetuate school and societal inequities. 
Gill was hired to teach first grade in the same urban school district where she had student taught - not the same school, but at the same grade level that she had student taught. This meant that Gill was already familiar with many aspects of the curriculum, procedures, and processes of the school district when she began her first year. In keeping with the policy in her school district, Gill was assigned an official mentor, who was charged with meeting with her over the course of the year, and she also was required to attend a number of meetings to orient new teachers to the district.

Like many new teachers, Gill struggled her first year. This is not surprising. In fact, my own research on learning to teach (Cochran-Smith et al. 2009, 2012; McQuillan et al. 2009a, 2009b) - along with studies by many researchers in many different contexts and countries -indicates that most new teachers struggle, and many experienced teachers who look back on their first year openly acknowledge that their work at that time was far from ideal.

\section{The Tale of Elsie Reynolds}

Like Gill, Elsie Reynolds is a white, female, middle class woman. She was a little younger than Gill, entering the teacher-preparation program right out of college in her early 20s. Like Gill, Elsie also had a strong academic background. She attended a prestigious liberal arts college in the northeastern United States (not the same one as Gill) where she majored in English literature. She had been a strong high school student who had participated in nearly all honors and other advanced courses. She scored quite high on the standardized $\mathrm{GRE}^{\circledast}$ exam, which is used for entrance into graduate school. In fact, she had the highest GRE score among the 22 teachers in the case studies research project from which her story originates, and she later also scored very well on the teachers' test required by the state of Massachusetts.

Elsie began her teaching career with a strong commitment to the profession. But unlike Gill, Elsie told our research group in an early interview that she planned to make teaching her lifetime's work. Like Gill, Elsie attended a major research university for teacher preparation (again, not the same one as Gill), enrolling in a one-year master's degree program. Elsie earned initial teaching certification at the secondary level in the subject area of English. The education school at Elsie's university was ranked within the top 20 schools of education in the country. She chose this university over two others because of its location and its reputation for providing a strong secondary teacher-preparation program. Elsie's preparation program was organized around several themes, including preparing teachers to work for social justice, in part by meeting the diverse needs of all students. The program also emphasized inquiry and classroom research. 
Elsie was hired to teach English at the same high school where she did her student teaching. According to policy studies, this is important. The studies point out that one cause of early attrition from teaching is the difficulty caused when new teachers are assigned to teaching jobs that are outside their field of study or outside the school level for which they were prepared (Liu 2002). Elsie was officially assigned a school mentor, the English department head at her school.

Like Gill, Elsie struggled her first year. Again, we know that many new teachers struggle-with the practicalities of teaching and managing a classroom; with the competing demands of administrators, parents, and colleagues; with the necessary juggling of multiple tasks and meeting the needs of many different learners; andoften-with the realization that their own expectations (and sometimes their dreams) about teaching do not match up with the reality of the work and with the weight of the responsibility for a group of students.

By now it should be clear that these two tales have many similarities. One could argue, perhaps, that some of these are just surface similarities. But many of them speak to factors that policy makers and others often claim are critical to improving teacher quality: strong academic background; solid subject-matter knowledge; preparation at a high-caliber institution; commitment to teaching; first-year teaching placement aligned with the teacher's subject field, certification area, and experience during the student teaching period; and designation of a formal mentor with some experience.

Despite these similarities, however, the conclusions of these two tales are strikingly different. Gill Maimon has now completed 17 years of full-time classroom teaching in the same large, urban public school district in which she began. Meanwhile, toward the end of her first year of teaching, Elsie Reynolds was informed she would not be rehired the following year, and she subsequently decided to leave teaching altogether.

\section{What Made the Difference?}

What explains this tale of two teachers and their strikingly dissimilar outcomes, especially given the just as strikingly similar aspects of their stories? What really made the difference?

To answer this question, I examined four features of these two teachers' experiencefeatures that seemed to make the difference in what happened to them as new teachers and how they did or did not learn to teach over time: deprivatization of practice; high expectations for all students and for oneself as a teacher; inquiry as stance on 
the work of teaching; and multiple, overlapping learning communities (see Figure 1). It is important to emphasize that these four are highly interrelated and overlapping aspects of the process of learning to teach over time, not discrete or independent factors. It is also important to note that how these features play out in the experiences of these two teachers - or any individual teacher-depends on the individual as well as on multiple social and cultural contexts.

\section{Figure 1. Learning to Teach Over Time: \\ Four Features of Practice}

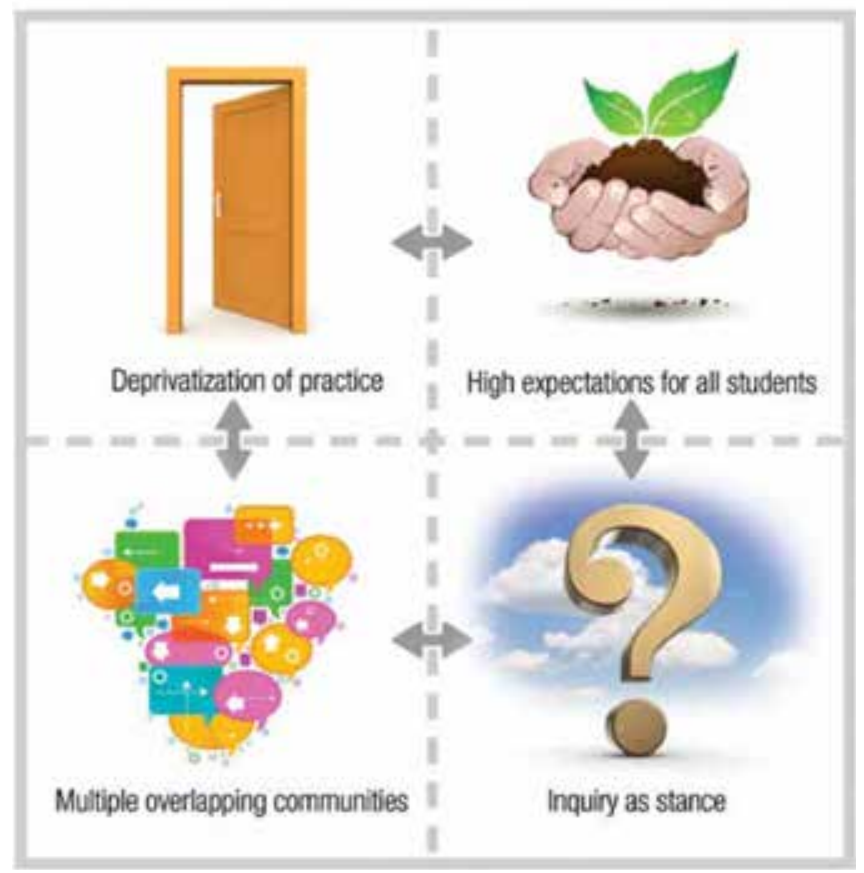

One way to think about the differences in the two teachers' experiences is that these four features were shaped by the ongoing interactions of various contexts. These contexts include:

- individual beginning teachers' values, beliefs, expectations and dispositions;

- their entry characteristics, including academic background and demographics, as well as family and personal situations; 
- the nature of their opportunities to learn during the teacher-preparation period (which includes opportunities in coursework, fieldwork, community experiences, and other contexts) as well as opportunities to learn in ongoing professional development activities beyond the preparation period; and

- school, community, and larger cultures and contexts, including conditions, constraints, accountability systems, and available resources and supports.

All of these contexts are dynamically interrelated, not separate, and they change over the course of time (see Figure 2).

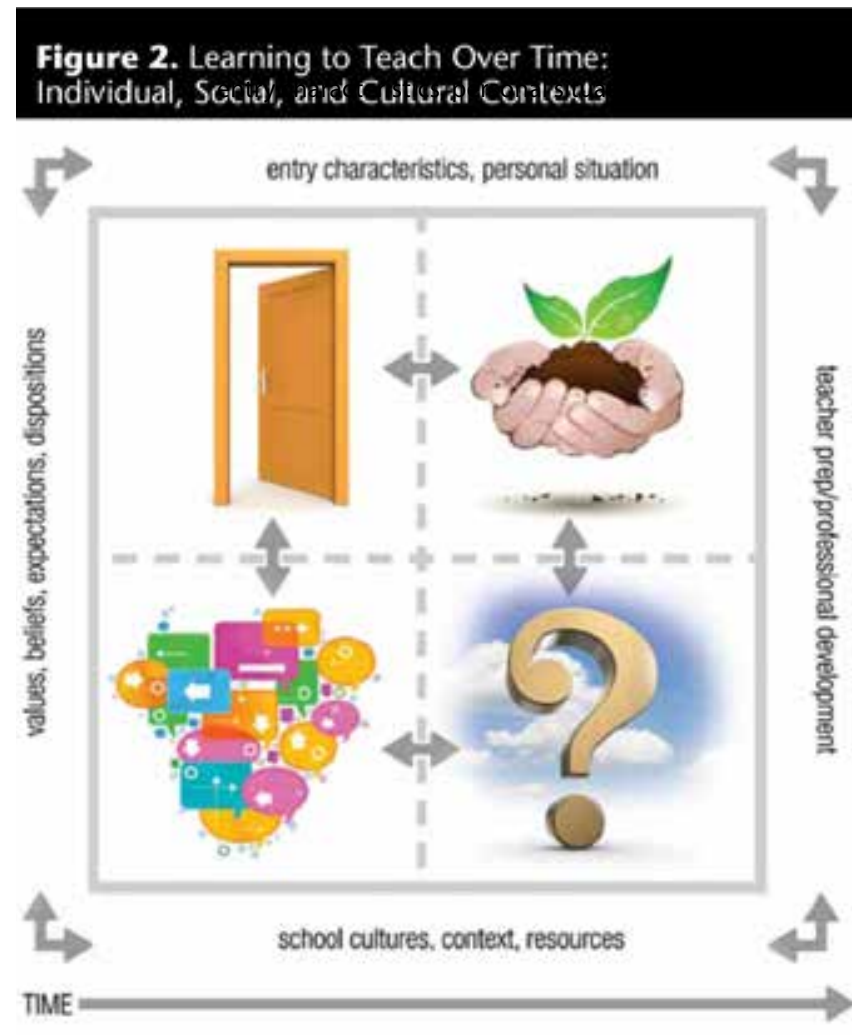

\section{Deprivatization of Practice}

The term "deprivatization" has been used in educational theory and research by a number of people working from different theoretical frameworks and traditions to refer to various aspects of pedagogy, teaching practice, school change, classroom documentation, and other related concepts (e.g., Spillane and Seashore Louis 2002; Fullan 2007; Stoll and Seashore Louis 2007). I use this term here to call attention to the 
fact that for many years, teaching has been regarded as privatized work. Although this view has changed somewhat in some schools, teaching has been taught to new teachers, studied by researchers, and evaluated by administrators as a largely individual and private activity, something that takes place mostly behind the closed doors of individual classrooms and in isolation from other teachers and colleagues. Privatization has traditionally made teaching lonely and isolated work, but-and there is a doubleedged sword here-it has also afforded a certain amount of autonomy and privacy from the scrutiny of others (Little 1990; Cochran-Smith and Lytle 1993).

Deprivatization of practice, put simply, is the interruption of teaching as a private act. The change is brought about through a variety of perspectives and processes that open up teaching to others and prompt collaboration with others who are also engaged in the effort to make their work public and open to critique. The upside of deprivatization is the end of isolation-with, instead, collegial support, the joint construction of knowledge, and the mutual work of collaborators in communities. But, in certain contexts and circumstances, as is clear in this tale of two teachers, deprivatization also can be threatening and can increase anxiety and vulnerability.

In the tales of the two teachers introduced earlier, privatization and deprivatization played major, but complicated roles. As noted, both Gill and Elsie struggled during their first years. A fair amount of the struggle for each of them had to do with classroom management, the practicalities of teaching, and their attempts to deal with the tensions between the ideal teaching they envisioned and the realities and constraints of their classrooms.

Deprivatization and the Tale of Gill Maimon. Gill said in an interview that she finished the preparation program most in need of the practical pieces of teaching - that she was much better able to talk about and analyze teaching than actually do the work. As I noted, she got a job in a large school in the same school district where she had student taught. She became increasingly aware during the first year that her practice was, in her word, "sub-par," and that she did not have the systems, organizational strategies, and approaches that she needed to improve. Frantic for solutions, Gill reported, she was constantly trying everything she saw anyone else doing, which was not only exhausting, but also not true to herself. She struggled mightily to get what she termed "her system of justice" figured out and established in the classroom.

Gill commented that her principal did not welcome her reflective stance. Her officially designated mentor barely offered any support; in fact, she never showed up in person to help her. Near the end of the school year, the mentor arrived at Gill's 
door and asked her to sign off on a school district form indicating that they had met periodically throughout the year; the signed form was required so the mentor could receive payment for her task. She was surprised_and not pleased—when Gill declined.

Fortunately for Gill, there was an experienced teacher who took her under her wing, advocated for her in several issues with the principal, and defended her as a professional colleague. And there were grade-level partners who were generous in sharing materials and ideas.

Nonetheless, she reported that, increasingly during her first year, she felt she was just "bad at teaching." In what she called an act of "desperation," Gill began to attend the Teachers Learning Cooperative (TLC), which turned out to be a crossroads for her in terms of deprivatizing her practice (though she did not use that word or concept). TLC is a teacher-initiated, teacher-led, and teacher-run cross-school group of teachers committed to urban education. The group works from the assumption that intellectual capacity is widely distributed across human beings and also assumes that teachers' work improves when they have opportunities to document it and critique it with other teachers in structured ways.

Gill had learned about the group during her teacher-preparation program. In several of her courses, the writings of TLC members and other teacher groups and individuals were included as part of the reading on course syllabi. In addition, teachers from TLC and other teacher groups made presentations about their work in the program courses and in monthly meetings of teacher candidates and their cooperating teachers, which were part of the program. And many teachers from TLC and other established teacher groups served as cooperating teachers and supervisors in Gill's preparation program. The work of this group was consistent with the perspective of the preparation program that learning to teach is a lifelong process wherein everybody is a learner-everybody opened up their work to others by deprivatizing it so all could learn from it. Gill reported that the teachers' group and the colleague who advocated for her were her saving grace during that first year.

Deprivatization and the Tale of Elsie Reynolds. Compared to Gill's experiences, Elsie's experiences were somewhat similar — but at the same time, very different. A week before beginning her first year, Elsie told us she felt fairly confident; although when asked about her goals for the year, she said she really just wanted to survive the first year and "do no harm at the very least." As the year progressed, however, Elsie's enduring challenge had to do with classroom management and discipline. She struggled with students who did not do homework and with rowdy behavior in some of her classes-attributing 
these problems alternately to her own too relaxed manner, the difficulty of the group, the many undiagnosed learning and behavior problems in the school, and her own struggle to become an authority figure.

Elsie's classroom was located in the "annex," a separate wing of the school building, physically removed from the rest of the English teachers and other academic teachers, and directly across from the art teacher's room. On one side, the room had windows that looked onto the hallway. As the year progressed, Elsie expressed frustration. She felt detached from the rest of her department and, because of the windows, quite exposed-her troubles with classroom management on display. Elsie's official mentor was the English department head, who observed her once during the school year as did the assistant principal. Neither reported problems nor gave feedback. In an interview at the end of the year (after she had been informed she would not be rehired), Elsie's mentor told us he had left it to Elsie to ask for help. "She could have reached out if she needed support," he said.

Soon after Elsie had received the news that she would not be rehired, Karen Shakman, the researcher from our project, arrived at her classroom to observe and found that the windows of the classroom had been papered over so no one could see out or look in. Elsie explained that she had felt like she was in a "fishbowl," particularly because of her tense relationship with the art teacher across the hall. This act, and the fact that she had asked for and been granted permission from the administration to put up the paper, speaks to the school's culture of isolation and to Elsie's own increased anxiety. The papering of the windows was the culmination of months of neglect and isolationa metaphor for Elsie's lack of ongoing support and her halted professional growth. Elsie never did receive a clear statement about why she was not rehired, although her assumption was that it had to do with student discipline issues. Neither of the two brief visits to her classroom by school administrators included follow-up.

One of the central differences in these two teachers' experiences during the first year had to do with what they did and where they turned when things were not going well. Gill went in the direction of deprivatization, while Elsie turned inward, making teaching more and more private until the final point, after she had been let go, when she papered over the windows of her classroom.

Of course, these different directions have to do with the interaction of multiple factors, as noted earlier. Individual teachers-who they are, what they bring with them to teaching, what their characteristics are-matter a lot. But this is not simply about teachers' personalities or people who are either "born" or "not born" to be teachers. 
This also has to do with how teachers' characteristics interact with the resources that are available, what they learn in their teacher-preparation programs, what kinds of opportunities they have to critically reflect and work with others, and what the cultures of their schools are like.

Based partly on her character and the learning opportunities she had, Gill knew where to look for help, but she also knew what to look for-a way to deprivatize teaching and a teacher group where asking questions and admitting uncertainties were not seen as signs of failing, but as signs of learning. Elsie, on the other hand, who struggled with developing a teacher voice and an identity as a teacher, also entered into a school with a culture of isolation that only grew stronger as she experienced difficulty and uncertainty.

The second factor that played a major part in differentiating this tale of two teachers is high expectations for all students and for oneself as a teacher. Specifically, it is important for teachers to assume and then act on the assumption that all students are makers of meaning and all are capable of dealing with complex ideas. Having high expectations for all students means providing opportunities for all of them to learn academically challenging knowledge and skills. Akin to high expectations for students, this second factor also includes teachers having high expectations for themselves, working from a sense of their own efficacy as decision-makers, knowledge generators, and change agents. As with deprivatization, expectations played an important, but complicated role in this tale of two teachers.

High Expectations and the Tale of Gill Maimon. Gill entered the teacher-preparation program because she believed strongly in public education, and she wanted to be part of the larger effort to rectify an unjust educational system. However, during her preservice year, Gill was a student teacher in a class of 16 first-graders in a primarily working class elementary school in urban Philadelphia. Her class was uncharacteristically small because, as she wrote at the time, the children "were skimmed from the perceived 'bottom' of the first-grade population"-that is, they were children who had been designated "at risk" of academic failure by their kindergarten teachers, ear-marked for remedial instruction, and expected to spend at least two years in first grade. Over time, it became clear that Gill's cooperating teacher had low expectations for these students. She was not a good role model, and her practices were not consistent with what Gill was learning in her program.

But Gill resisted the negative influence of her cooperating teacher. In a project she completed as part of her preparation program, for example, she worked with a small 
group of children in a literature study group to explore multiple versions of the Three Little Pigs story. In one session, Gill had the children draw pictures of their favorite story characters. She wrote:

I found Timmy's sympathy for the wolf so interesting that I wanted to include the entire class in our exchange. After Tim described his picture to everyone, I asked him, "Do you think the wolf deserved to be eaten at the end of the book?" He answered with a definite no. He explained. "You know why? Because the pig was mean. He came at different times and he wasn't waiting for the wolf. It wasn't fair. That's why he shouldn't get eaten." In response, Colleen stated strongly that the pig's deception was a necessary evil. "He had to do that or he would have been eaten." I quickly polled the room to see who stood where on this wolf issue. Based on the responses I received, I paired up individuals with classmates who held opposing opinions and asked each group member to try to convince the other.

In the days that followed, Gill and her students explored many versions of the classic story as well as parodies of the tale that played with point of view, narrator reliability, and novel characters.

In writing about the project as a whole, Gill said she had learned that a small group of "at risk" first-graders could indeed engage in quite sophisticated work, debating points of view, seeking textual evidence, and comparing/contrasting multiple versions. In her conclusion, she reflected on her children's abilities as learners and the damaging effects of a learning culture based on low expectations:

I have been told so many times, "You can't do this because they can't do this," and "You don't understand the way you have to teach these children." .. In response, I hold up the powerful, angry, excited, exciting, deep, enlightening, funny, brave, complex, strong responses that these "at risk" students produced over the course of our literature study. Our exploration has been their and my vindication.

It is well-known that teachers frequently "dumb-down" the curriculum for "the low group" and for "at risk" students (Haberman 1991). However, supported by the many communities in her preparation program, Gill resisted the pressure to work from lowered expectations, instead providing rich learning opportunities and documenting her students' intellectual abilities to reason, debate, and compare. She maintained her high expectations for all students and for herself as a teacher and activist, committed to enhancing students' life chances. 
High Expectations and the Tale of Elsie Reynolds. Elsie Reynolds also entered teacher preparation with high expectations. She wanted to expose students to great literature and inspire them in the way she had been inspired. She also wanted to relate to students and show that she cared about them. The teachers she remembered as role models from her own school experiences not only had strict expectations about students' work, but also related to them as whole persons.

In her preparation program, Elsie had learned about engaging students in critical thinking and about using collaborative group work and other nontraditional teaching methods. She saw some of these demonstrated in her first fieldwork experience, but not in her student teaching classroom, which was the same school from which she was eventually released. She tried to implement various approaches, but Elsie's cooperating teacher thought her expectations were too high. Over time, Elsie herself came to believe this. Midway through the student teaching period, when she was asked in an interview about expectations for students, she said:

I really do think [my expectations] were too high.... I had always been in honors classes when I was in school. So I think my expectations were a little beyond what they had been taught and what they were capable of. And so in that sense, when you say did you maintain high expectations, that implies that ... it's always bad to put the bar down a little bit. But if you're dealing with someone who's two feet tall, and you put the bar 20 feet up, [that's just] not gonna happen. So what I did, what I had to do, was assess where they were and set high expectations for where they would get to at the next point.

Based on our observations in Elsie's classroom and our analysis of her assignments and assessments of students, it appears that what Elsie actually did, as she endeavored to adjust her expectations, was to move mostly toward more direct instruction and spoon-feeding of the factual information that would be on a test. She began to rely on handouts that boiled down important information and then gave quizzes that required students to regurgitate that same information.

Elsie clearly grappled with the issue of expectations and with the gap between her ideals as an English teacher and what she eventually came to perceive as the level of the students she was teaching. In a certain sense, the students themselves were Elsie's most significant instructors in her first year. They had been socialized to expect particular relationships with their teachers and were accustomed to particular levels of effort. From them, Elsie learned to expect lower level work and ask for less. This phenomenon reflects what some researchers have argued is an unspoken agreement (Kennedy 2005) - a kind of Faustian bargain — between teachers and students in which teachers 
do not ask a lot from students in exchange for a certain amount of calm and order in the classroom. Over time, Elsie's expectations eroded.

What accounts for the very different level of expectations these two teachers held for their students and for themselves? Just like the issue of deprivatization, high expectations depend in part on the personal characteristics and identity of the teacher and in part on how these interact with the culture of the school. And, of course, Gill was dealing with young children just beginning school, while Elsie struggled with the distinctive difficulties posed by adolescents who had long ago learned how to "do" school. But the differences go beyond these individual circumstances. Gill's preparation focused explicitly on principled resistance, advocating the idea of "teaching against the grain" (Cochran-Smith 1991) of the cultures and arrangements of schooling that foster inequities. Although Elsie's preparation program emphasized social justice, her placement situation, some personal health issues, lack of support, and the pervasive culture of the school eventually wore her down and socialized her into lower expectations.

The third feature that differentiates the two teachers in this tale is "inquiry as stance," the title phrase of my book about practitioner research, coauthored with Susan Lytle (Cochran-Smith and Lytle 2009). Inquiry as stance is a concept we developed a number of years ago to emphasize that teacher inquiry is a world view, a critical habit of mind, and a way of knowing about teaching that carries across the professional continuum and across educational settings. The idea of inquiry as a stance contrasts sharply with inquiry conceptualized as a time- and place-bound classroom research project and with inquiry as a method or set of steps for solving problems.

Fundamental to inquiry as stance is the idea that educational practice is not simply instrumental in the sense of figuring out how to get things done, but also and as importantly, it is social and political in the sense of deliberating about what to get done, why to get it done, who decides, and whose interests are served. In this tale of two teachers, approaches to inquiry were dramatically different.

Inquiry as Stance and the Tale of Gill Maimon. In an interview, Gill told me that when she started her teacher-preparation program, the concept of inquiry and of being a teacher researcher was revolutionary to her, but she was very comfortable with it. She considered herself fortunate to be among the "lucky people [who] find work that matches how they want to see the world." She said, "I aim to be truthful, to want to know what's really going on in my classroom from different perspectives, always knowing that I only see a slice." For Gill, inquiry as a stance on teaching fit perfectly with, 
in her words, "how she was wired." Because her preparation program was so cohesive in its approach, she said inquiry soon became an internal frame for her, which was extended by the professional groups in which she participated.

Gill's own words speak far better than mine could about her inquiry stance as a teacher over time. In a chapter titled, "Practitioner Inquiry as Mediated Emotion" (Maimon 2009, 213), Gill wrote:

I have never been certain whether I am a teacher who writes or a writer who teaches.... Over thirteen years in first, second, and third grade classrooms in the School District of Philadelphia, writing and teaching have become richly and inextricably intertwined. I am always endeavoring to create meaning from the perpetual ambiguity that accompanies the work that I do in the world. It is for this reason that I have kept a teaching journal throughout my career. ...One of the reasons I write about my classroom is to challenge the limits of the work, to keep trying to know more. ... intentionally observe and describe day-to-day life in my classroom in order to extend the boundaries of what I am able to perceive.

Gill's theorizing about the role of inquiry and writing in her work as a teacher clearly reflects how she thought about her everyday classroom experience, which she regularly wrote about in a teaching journal.

Following her observations of her first- and second-grade students during a high-stakes testing period, she wrote:

It is not hard to come to a conclusion that, on a test like this, the fact that the children know so much sometimes makes them appear not to know enough. A great example of a [test] question that disadvantages good writers is this one, which asks students to complete a sentence by writing a word or words in a blank space: "My turtle to be alone." It seems clear that the test makers anticipate answers like, "wants" or "likes" or "hates" or even "does not want" or "does not like." From the miniscule size of the space, I can tell that they do not expect an answer like Frank's: "My turtle must go into the street to be alone." In attempting to fit this entire answer into a too small space, Frank spells everyword flawlessly, but so cramps them together that they are barely intelligible to me, one who is very familiar with his work. To a person not fluent in Frank, I suspect that the correctness of his answer will not be recognized. Maybe Frank should have been more savvy and kept his answer clear and simple. If so, then maybe I have done him a disservice, because I am teaching him to write, not to fill in blanks efficiently. 
Gill later wrote, "The writing I do is an assertion of the inherent intellectual nature of teaching. It is a way that I keep learning."

Inquiry as Stance and the Tale of Elsie Reynolds. Elsie's experience with inquiry is dramatically different from, and much briefer than, Gill's. Although Elsie's preparation program was intended to focus on inquiry as stance, in actuality it fostered a view of inquiry as project. As noted previously, the notion of inquiry as stance contrasts sharply with inquiry as a time- and place-bound classroom research project. When inquiry is a project, the underlying message is that it is something turned off and on at given points in time, with very clear lines separating teaching and inquiry.

Elsie did not get a great deal out of the inquiry project she was required to do during student teaching. The question she decided to research was whether or not teaching students grammar based on their own writing is an effective teaching strategy. But her conclusions, contrary even to some of her own data, simply reinforced her initial belief that this was a good form of instruction. She formed no new insights or fresh perspectives, and she posed no additional questions that stretched her thinking. In fact, Elsie found doing the research project overwhelming on top of the expectations of student teaching, and she thought it was too difficult to do both simultaneously. Elsie explained:

I just don't think it works very well, throwing [inquiry] on top of [student teaching because with] student teaching, there was just so much that I was learning and there was so much I was trying to figure out how to do that ... it was hard for me.... It's hard enough to plan lessons in general when you're student teaching. But it's harder to plan out an entire research project through lessons.

Her cooperating teacher agreed.

The responses of both Elsie and her cooperating teacher speak to the fact that the preparation program conveyed-albeit unintentionally-the message that inquiry was separate from the work of teaching, rather than an integral and ongoing part of it that actually helped participants to be better teachers. Although Elsie would probably have benefitted from learning about the idea of inquiry as a way to interrogate her own assumptions as a teacher and as a way to understand more deeply what was happening in her classroom, this was not what she learned about inquiry from her preparation program. Rather, inquiry was one more requirement to be checked off an unreasonably long list. 
The experiences Gill and Elsie had in terms of inquiry were as different as night and day. The notion of inquiry as stance resonated immediately with Gill, while Elsie found the inquiry project an annoyance. Of course, it is not clear how Elsie would have responded to an approach where inquiry truly was conveyed as a stance. What is clear is that Elsie never had that opportunity, primarily because of the approach of the teacher preparation program itself.

The fourth feature that differentiated Gill's and Elsie's experiences as teachers is the opportunity to be part of multiple overlapping communities. A great deal has been written over the last ten years or so about teacher learning in communities, often referenced as inquiry communities, teacher learning communities, professional learning communities, collaborative learning communities, and other terms (e.g., Lieberman 2000; McLaughlin and Talbert 2006; Stoll and Seashore Louis 2007). When Susan Lytle and I discuss communities (Cochran-Smith and Lytle 1993; 1999; 2009), we are careful to point out what we do not mean by that term - that simply having teachers meet as a group is a good thing, or that something magical happens just by virtue of people coming together. Of course, it is the work that gets done in those groups that matters. The essential purpose of communities, as we have tried to conceptualize and live in and with them for the last 25 years, is to foster teacher learning over the lifespan and link practitioners with larger social and school change efforts.

From our perspective, learning from inquiry means that members of communities work together to question their own assumptions and pose problems of practice that require studying their own students and schools. Inquiry communities also foster new relationships that alter older expert-novice models of proficiency and replace the singular pursuit of best practice with considerations of practice finely tuned to local histories, cultures, and communities. The idea of teachers learning in communities is closely related to, and intertwined with, the other features I have written about so far: deprivatizing teaching, maintaining high expectations, and working from an inquiry stance. Gill's and Elsie's experiences with communities were vastly different.

Communities and the Tale of Gill Maimon. Gill's preparation program was organized around nested communities: teacher candidates moved through the one-year program in a tight cohort group, and 3-5 student teachers were grouped together for placement at the same school. Although each student teacher had an individual cooperating teacher, all the students at a given school, their cooperating teachers, and their university supervisor met weekly as a teacher researcher group on the school site, and all the teacher researcher groups from the different schools met monthly with other teacher educators at the university. In addition, the student teachers and 
their supervisor from one school site cross-visited for a two-week period with the cooperating teachers at another school site, engaging in activities planned by the hosting school group. Meanwhile the university supervisors and teacher educators met biweekly as an inquiry group to scrutinize their own work as mentors.

As alluded to earlier, Gill's cooperating teacher seemed to have low expectations for the "at risk" students in her class and did not turn out to be a good role model or helpful mentor for Gill. But because of the multiple overlapping communities intentionally built into the program, many other mentors were accessible, which assuaged the difficulty caused by the one-to-one mismatch that may occur when mentors are assigned to student teachers or to new teachers. Mary Kate Cipriani, Gill's closest fellow teacher candidate during the program and a member of her school site group, described the importance of communities in learning to teach in a paper she wrote at the end of the program:

My salvation became the teacher communities I [was part of]... The term "communities" is used broadly because it encompasses many kinds of support groups and moments. It includes the mornings when the other student teachers who taught with me at the school would come by my classroom to ask me questions that ranged from "Have you ever used pattern blocks?" to "How are things going in your life?". . It includes the [conference] paper group and the Sunday nights we spent beside our professor's fireplace going over our journals and papers, looking for themes. It includes my cooperating teacher and me chatting about our students' academic behavior and who likes whom this week. It includes dinners at my supervisor's house, classes at [the university], and special events like the conference where we presented our teacher research.... I am a teacher because we are a teacher community; and because we are a teacher community, I am a teacher.

When I interviewed Gill and asked her to look back on her experiences learning to teach, she spoke at length about the multiple overlapping teacher communities she had been part of, both during the teacher-preparation period and moving forward.

She said she had had multiple mentors who helped her with the day-to-day as well as the big picture aspects of teaching. She talked about learning from cross-visiting other teachers during the preparation program. The Philadelphia Teachers Learning Cooperative played a critical role in Gill's learning over time, partly because there were others there who had had the experience of being in opposition to the administration in honorable ways; their convictions reinforced her beliefs and values about teaching. Gill said that when she switched schools after her first three years of teaching, the principal at the new school, more than anybody, helped her learn more about the practical pieces of teaching. 
Over the years, Gill was also part of the Philadelphia Writing Project, and she served as the math leader for her school and as a participant in the school's "small learning communities" approach. After five years of teaching, while she continued to teach fulltime, Gill began a doctoral program, which opened up many new avenues for critical reflection and created another central community for understanding teaching, learning, and schooling. After a few years, Gill hosted student teachers in her own classroom nearly every year. She also mentored new teachers and opened up her classroom to frequent visitors, including parents, fellow teachers, university researchers, observers, and guests.

When asked in an interview to identify the key to mentoring beginning teachers, Gill replied without hesitation that the key was also the major problem with so many official mentoring programs: the fit between the mentor and the new teacher. This was true, she remarked, because a mentor-to a certain degree-has to be a person who shares your philosophy, even though there are many ways to do the work of teaching well.

As Gill pointed out, if one mentor does not fit (and as illustrated earlier, neither Gill's cooperating teacher during student teaching nor her official mentor during her first year fit well at all), then there better be another mentor-or group-to approach to talk, try out, and relate. Reflecting on her early years of teaching, Gill said it was not the presence or absence of a mentor, which is a support service for new teachers often built into state-level policies, but the overlapping and multiple opportunities she had had to be part of pairs, triads, small groups, larger groups, cohorts, communities, cooperatives, and inquiries that had helped her learn to teach and continue learning to teach over time.

Communities and the Tale of Elsie Reynolds. It is difficult to write about Elsie's experience with communities, because it is so diametrically different from Gill's. It was not simply that Elsie lacked multiple and overlapping communities; she had practically no community at all. In part because of the unusual nature of her placement at a school that did not have an ongoing partnership with the preparation program and in part because of her personal health limitations, Elsie had much less support from the program than she normally might have. Although she participated in the program's required activities, including several "content mentoring sessions" with other English teachers and English professors at the university, which she found helpful, those activities were limited in number and scope. 
It is important to note here that Elsie's does not represent the usual experience of teacher candidates in her program. In fact, she is a stark-and extreme-example of learning to teach in isolation. Although devastating in terms of its outcomes for her individually, her experience is almost a case study in what not to do in terms of establishing community and supporting new teachers' learning. Her mentoring arrangement during her first year, which was intended to be a one-on-one relationship, existed in name only. In addition, during her first year of teaching, she was physically separated from the other faculty, and her mentor expected her to ask for help if she needed it. It turned out that Karen Shakman, the core researcher on our team who collected data about Elsie over two years, was the only person who observed her with any regularity and, according to Elsie, the only person who communicated regularly with her about teaching and asked her how she was experiencing the work. In the end, then, it is not surprising that Elsie's overall experience was one of isolation rather than community.

Again, what made the tales of these two teachers so different, at least during their preparation programs and their first year of teaching, had partly to do with who they were-their expectations, entering characteristics, and personal situations. But it also had to do with the social, organizational, and intellectual contexts that supported (or did not support) their learning in the school cultures and contexts in which they worked.

It also had to do with opportunities (or lack thereof) for ongoing professional development in a whole range of learning communities. For Gill, there were multiple opportunities available in her program and, to a certain extent, in her schools. But throughout her 17 years of teaching, she also sought out communities that made the possibilities richer and more revealing. Elsie, on the other hand, participated in few community activities within her program, and there were virtually no communities for her to be part of in her first-year school. Her isolation was exacerbated by her turn inward and her gradual withdrawal inside her classroom.

\section{A Tale of Two Teachers: Conclusion}

The stories of Gill and Elsie are connected to three larger issues related to learning to teach across the continuum of the professional lifespan. First, as these two stories make clear, what determines how new teachers fare is not the presence or absence of single factors - age or previous work experience, strong subject-matter knowledge, attendance at a selective institution, in-field or out-of-field placement in the first job, or having a mentor versus not having one-even though these are often the focus 
of policy and critique. Policies and practices that attempt to improve teacher quality and teacher retention by manipulating singular aspects of teacher selection and recruitment, of teacher preparation, or of resources for new teachers, such as the provision of mentoring or induction programs, are unlikely to succeed.

The second point, related to the first, has to do with teacher quality, teacher learning, and teacher education. To support teacher learning across the continuum and to build teachers' capacity for improvement, we must take into account teachers' multiple identities, positions, roles, and ways of knowing. Addressing these considerations will require multi-layered policies and practices regarding initial teacher education, induction, and professional development that reflect the idea that teachers are not all the same and do not experience policies and practices in the same ways. How values and beliefs interact with background characteristics, teacher preparation and professional-learning programs, and the cultures and contexts of schools will have to be taken into account.

The third point is that communities for teacher learning must be contexts where questions and uncertainty are understood as signs of learning, not signs of failing. In a sense, this point ties together the four key features that differentiated the stories of the two teachers described here: deprivatization, high expectations for teaching and learning, inquiry as stance, and multiple overlapping communities. In Wayne Huebner's "The Vocation of Teaching" $(1987,26)$, he refers to teaching as a "pilgrimage" to emphasize the idea of learning to teach over time. He captures very eloquently the importance of teachers' ongoing learning as a critical part of all larger efforts to change schools and improve students' life chances:

Teachers must act in an imperfect world. To postpone action until the knowledge and technique makers establish the educational millennium is sheer irresponsibility, based on the illusion of progress. We have no choice but to risk ourselves. The choice is to consider the risk private or to build a community that accepts vulnerability and shares risks.

Learning to teach is something that happens over time, and it happens when new teachers work in the company of more experienced teachers who are also continuing to learn to teach.

This position contrasts dramatically with the ideas of some current policy makers and others involved in alternate approaches to teacher education, who believe that teachers should know how to teach effectively the minute they enter the classroom. From this perspective, effective teaching is defined as being able to raise students' test 
scores; and there is a clear notion that there are "best" ways to teach, regardless of who the students are and what experiential and cultural resources they bring. People who see things this way believe that school administrators should figure out as quickly as possible which teachers are effective at improving students' achievement and which ones are not, and then get rid of those who do not make the grade. This kind of thinking fails to acknowledge that learning to teach takes time, and it is never finished.

\section{Author's Notes}

These stories come from two different studies I have been involved in at two different universities at different points in time. The work of the first study appears in CochranSmith 1991, 1995a, 1995b, 1999, and 2000. The work of the second study appears in Cochran-Smith et al. 2009; Cochran-Smith, Gleeson, and Mitchell 2010; Cochran-Smith et al. 2012; McQuillan 2009a, 2009b; and Shakman 2009. These stories also draw on ideas from Cochran-Smith and Lytle 1994, 2009; Maimon 2009; and Shakman 2009. In particular, I am grateful to Gill Maimon and Elsie Reynolds, whose stories are told here, and Karen Shakman, who was the core researcher for data collection and analysis for the story of Elsie Reynolds.

Gill Maimon is the real name of the teacher who is described here. She prefers that her real name be used. Her story refers to experiences that go well beyond the first year, because her career in teaching is now quite a lengthy one. Elsie Reynolds is a pseudonym, as per the informed consent she signed for the study she was part of, wherein anonymity was assured. Her story is of much shorter duration. 


\section{References}

Cochran-Smith, M. 1991. Learning to teach against the grain. Harvard Educational Review 61(3): 279-310.

Cochran-Smith, M. 1995a. Color blindness and basket making are not the answers: Confronting the dilemmas of race, culture, and language diversity in teacher education. American Educational Research Journal 32(3): 493-522.

Cochran-Smith, M. 1995b. Uncertain allies: Understanding the boundaries of race and teaching. Harvard Educational Review 65(4): 541-70.

Cochran-Smith, M. 1999. Learning to teach for social justice. In The education of teachers: National Society for the Study of Education Yearbook, ed. G. A. Griffin, 98(1): 114-44. Chicago, IL: NSSE.

Cochran-Smith, M. 2000. Blind vision: Unlearning racism in teacher education. Harvard Educational Review 70(2): 157-90.

Cochran-Smith, M., and S. L. Lytle, eds. 1993. Inside/outside: Teacher research and knowledge. New York: Teachers College Press.

Cochran-Smith, M., and S. L. Lytle. 1999. Relationships of knowledge and practice: Teacher learning in communities. In Review of research in education, ed. A. Iran-Nejad and P. D. Pearson, 24(1): 249-305. Washington, DC: American Educational Research Association.

Cochran-Smith, M., and S. L. Lytle. 2009. Inquiry as stance: Practitioner research for the next generation. New York: Teachers College Press.

Cochran-Smith, M., A. M. Gleeson, and K. Mitchell. 2010. Teacher education for social justice: What's pupil learning got to do with it? Berkeley Review of Education 1(1): 35-61. Available at: http://escholarship.org/ uc/item/35v7b2rv.

Cochran-Smith, M., K. Shakman, C. Jong, D. Terrell, J. Barnatt, and P. McQuillan. 2009. Good and just teaching: The case for social justice in teacher education. American Journal of Education 115(3): 347-77.
Cochran-Smith, M., P. McQuillan, K. Mitchell, D. Gahlsdorf-Terrell, J. Barnatt, L. D'Souza, C. Jong, K. Shakman, K. Lam, and A. M. Gleeson. 2012. A longitudinal study of teaching practice and early career decisions: A cautionary tale. American Educational Research Journal. February 1. DOI:0002831211431006. Available at: http://aer.sagepub.com/content/early/ 2012/01/30/0002831211431006.

Fullan, M. 2007. Change the terms for teacher learning. Journal of Staff Development 28(3): 35-36.

Haberman, M. 1991. The pedagogy of poverty versus good teaching. Phi Delta Kappan 73(4): 290-94.

Hardy, B. 1978. Towards a poetics of fiction: An approach through narrative. In The cool web, ed. M. Meek, A. Warlow, and G. Barton, 12-23. New York: Antheneum.

Huebner, D. 1987. The vocation of teaching. In Teacher renewal: Professional issues, personal choices, ed. F. Bolin and J. M. Falk, 17-29. New York: Teachers College Press.

Kennedy, M. 2005. Inside teaching: How classroom life undermines reform. Cambridge, MA: Harvard University Press.

Lieberman, A. 2000. Networks as learning communities: Shaping the future of teacher development. Journal of Teacher Education 51(3): 221-27.

Little, J. W. 1990. The persistence of privacy: Autonomy and initiative in teachers' professional relations. Teachers College Record 91(4): 509-36.

Liu, E. 2002. New teachers' experiences of hiring in New Jersey. Paper presented at the Annual Meeting of the American Educational Research Association, April 1-5, New Orleans, LA.

Maimon, G. 2009. Practitioner inquiry as mediated emotion. In Inquiry as stance: Practitioner research for the next generation, ed. M. Cochran-Smith and S. L. Lytle, 213-28. New York: Teachers College Press. 
McLaughlin, M. W., and J. E. Talbert. 2006. Building school-based teacher learning communities: Professional strategies to improve student achievement. New York: Teachers College Press.

McQuillan, P., C. Jong, L. D'Souza, K. Mitchell, K. Lam, K. Shakman, A. M. Gleeson, S. Enterline, C. Power, and M. Cochran-Smith. 2009a. Some pieces that matter in teacher education: The synergy of social justice, inquiry-into-practice, and meeting the needs of diverse learners. Asian Journal of Educational Research and Synergy 1(2): 47-65.

McQuillan, P. J., L. A. D'Souza, A. J. Scheopner, G. R. Miller, A. M. Gleeson, K. Mitchell, S. Enterline, and M. Cochran-Smith. 2009b. Reflecting on pupil learning to promote social justice: A Catholic university's approach to assessment. Catholic Education: A Journal of Inquiry and Practice 13(2): 157-84.
Shakman, K. L. 2009. Embracing the tensions: A qualitative case study of learning to teach in a social justice teacher education program. Unpub. PhD diss., Boston College, Chestnut Hill, MA.

Spillane, J. P., and K. Seashore Louis. 2002. School improvement processes and practices: Professional learning for building instructional capacity. National Society for the Study of Education Yearbook, ed. J. Murphy, 101(1): 83-104. Chicago, IL: NSSE.

Stoll, L., and K. Seashore Louis. 2007. Professional learning communities: Elaborating new approaches. In Professional learning communities: Divergence, depth and dilemmas, ed. L. Stoll and K. Seashore Louis, 1-13. Berkshire, England: Open University Press/ McGraw-Hill.

Marilyn Cochran-Smith is John E. Cawthorne Chair in Teacher Education for Urban Schools at Boston College's Lynch School of Education. She was invited to the Laureate Chapter of Kappa Delta Pi in 2003 and served on the KDP Executive Council for the past two years. 